\title{
Etiology of gastrointestinal bleeding in children referred to pediatric wards of Mashhad hospitals, Iran
}

Seyed Ali Jafari ${ }^{1}$, Mohammad Ali Kiani ${ }^{1}$, Hamid Reza Kianifar ${ }^{2}$, Mohammad Mansooripour ${ }^{3}$, Elahe Heidari ${ }^{4}$, Maryam Khalesi ${ }^{5}$

${ }^{1} \mathrm{MD}$, Associate Professor, Department of Pediatric Gastroenterology, Faculty of Medicine, Mashhad University of Medical Sciences, Mashhad, Iran

${ }^{2}$ MD, Professor, Allergy research Center, Faculty of Medicine, Mashhad University of Medical Sciences, Mashhad, Iran

${ }^{3} \mathrm{MD}$, Faculty of Medicine, Mashhad University of Medical Sciences, Mashhad, Iran

${ }^{4}$ MD, Assistant Professor, Department of Pediatrics, Faculty of Medicine, Mashhad University of Medical Sciences, Mashhad, Iran

${ }^{5} \mathrm{MD}$, Assistant Professor, Department of Pediatric Gastroenterology, Faculty of Medicine, Mashhad University of Medical Sciences, Mashhad, Iran

Type of article: Original

\begin{abstract}
Background: Gastrointestinal (GI) bleeding, which has several clinical manifestation and origins, is known as one of the most life-threatening events in children. Several etiologies have been suggested for GI bleeding.

Objective: To determine the most important causes of GI bleeding in children referred to Ghaem Hospital and Dr. Sheikh Hospital, Mashhad, Iran.

Methods: In this cross-sectional study, after obtaining written informed consent of their parents, 113 patients aging from newborn infants to 18-year-old children with GI bleeding admitted to Ghaem Hospital and Dr. Sheikh hospital were enrolled in this study from June 2012 to June 2014. After performing routine diagnostic and therapeutic procedures, a checklist containing all necessary information including demographic data, clinical history of patients, endoscopy and pathology findings, clinical and preclinical information were collected. The data were then analyzed using Statistical Package for the Social Sciences (SPSS) version 16.

Results: Of a total 113 study children, 61 (54\%) were male and 52 (46\%) were female. The results of this study showed that the most important causes of bleeding in upper GI among all admitted patients were prolapse gastropathy (18.6\%), esophagitis (15.9\%) and esophageal varices, gastritis, and coagulopathy (7.1\% for each). The main causes of lower GI bleeding were polyp (32.5\%), chronic nonspecific colitis $(20.7 \%)$, and proctitis $(18.2 \%)$.

Conclusion: Findings of this study indicated that prolapse gastropathy and esophagitis are more prevalent causes of upper GI bleeding. Furthermore, esophageal varices were more common in children older than 13 years. Polyp, chronic nonspecific colitis and proctitis are the most prevalent causes of lower GI bleeding.

Keywords: Gastropathy, Gastrointestinal bleeding, Endoscopy
\end{abstract}

\section{Introduction}

Gastrointestinal (GI) bleeding is one of the most life-threatening events in childhood $(1,2)$. GI bleeding is divided into three major clinical forms including upper GI bleeding, lower GI bleeding, and bleeding of obscure origin. Upper GI bleeding originates from the upper part of the esophagus to the ligament of Treitz, and is characterized by hematemesis and melena. Lower GI bleeding originates from distal of colon and is diagnosed with red blood cells in the rectum, especially in the absence of hematemesis. In bleeding of obscure origin, despite GI bleeding symptoms

\section{Corresponding author:}

Assistant Professor Dr. Elahe Heidari. Department of Pediatrics, Faculty of Medicine, Mashhad University of Medical Sciences, Mashhad, Iran. Tel: +98.9155574738, Email: Heidarie@mums.ac.ir

Received: March 12, 2017, Accepted: December 04, 2017, Published: February 2018

iThenticate screening: December 08, 2017, English editing: February 10, 2018, Quality control: February 15, 2018

This article has been reviewed / commented by four experts

(C) 2018 The Authors. This is an open access article under the terms of the Creative Commons Attribution-NonCommercialNoDerivs License, which permits use and distribution in any medium, provided the original work is properly cited, the use is non-commercial and no modifications or adaptations are made. 
including iron deficiency anemia, and positive occult blood test, no endoscopy or colonoscopy abnormalities are observed $(3,4)$. Bleeding may occur anywhere in the gastrointestinal tract and may be difficult to determine its location. GI bleeding that originated from the esophagus, stomach, and duodenum can be characterized by hematemesis (5). Excessive bleeding in the duodenum or upper GI system can also cause Melena $(6,7)$. The causes of lower GI bleeding vary by age, but anal fissures and juvenile polyps are the most important causes of lower GI bleeding $(8,9)$. Differential diagnosis of GI bleeding in children varies with age $(10,11)$. Upper GI bleeding in infants and young children is often due to ulcers and stress erosion, but in older children it may be due to duodenal ulcers, esophagitis and esophageal varices. Lower GI bleeding may occur due to a number of reasons such as fissure, polyps, allergies to milk proteins, inflammatory bowel disease, infectious colitis, Meckel's diverticulum, colon bleeding disorders and malignancies (11-14). Experience in different countries indicates the differences in the frequency of different causes of GI bleeding in children $(1,10,15$. Differences can be due to various causes including lifestyle, quality of health, nutritional habits, and geographical conditions. Studies have shown that in Iran, even among cities and different geographical regions of the country, there are significant differences in the prevalence and etiology of GI bleeding $(4,15,16)$. In this study, we aimed to investigate the etiologies of GI bleeding in children referred to Ghaem Hospital and Dr. Sheikh Hospital, Mashhad, Northeast of Iran.

\section{Material and Methods}

\subsection{Sampling and inclusion criteria}

In this cross-sectional study, the samples were children less than 18 years with patients with mild to severe GI bleeding admitted to Ghaem Hospital and Dr. Sheikh hospital. They were included when presented with GI bleeding to the emergency department, or reported the manifestations of bleeding e.g. hematemesis, ground coffee emesis, melena or rectorrhagia to investigate the etiology and the underlying pathology of GI bleeding. GI bleeding origin is distinguishable from the signs and symptoms. Patients, in whom the bleeding originated from nasal or oral cavity, or those who did not want to participate, were excluded from this study.

\subsection{Data collection}

In patients who had indication for hospitalization, the routine diagnostic procedures including physical examination and paraclinical tests (i.e. CBC, FBS, Pt, PTT, INR, BT, ALP, AST, and ALT) were performed. Then a checklist containing information on the demographic findings, history taking and physical examination of the patients, laboratory test results, imaging, ultrasound and endoscopy findings, and pathologies was prepared. The endoscopies were performed by an expert pediatrics gastroenterologist. Colonoscopy was done in cases with lower GI bleeding. So, both lower and upper bleeding were investigated in all the patients. The endoscopies were performed by 6-8 hours fasting in the children and four hours of discontinued breastfeeding. For colonoscopies, liquid diet with laxatives; polyethylene glycol powder and Senagol syrup (Goldaru co, Tehran, Iran) was started 48 hours in advance. Afterwards, clinical and preclinical information including duration of hospital stay, severity of GI bleeding (hemodynamic disorders or loss of hemoglobin) and response to treatment (recovery or death) were collected. The biopsies of all patients were obtained and sent for pathology assessment (fixed in formalin). The biopsies were checked by an expert medical pathologist and all of them were checked for Helicobacter pylori. All the patients were assessed by an expert pediatrics gastroenterologist, and final diagnosis was made based on all the mentioned diagnostic procedures. In cases of controversy, consultation with one other specialist was made to confirm the diagnosis. For other organ problems including hematology, the consultations were sent to other departments and diagnoses were made based on the clinical examination and laboratory tests.

\subsection{Statistical analysis}

According to the literature (30), and the frequency of an important cause of bleeding (inflammatory bowel disease), the sample size was calculated as 113 patients, using statistical formula with $95 \%$ confidence interval and an accuracy of 5\%. SPSS software (SPSS Inc. Released 2007. SPSS for Windows, Version 16.0. Chicago, US) was used for statistical analysis, and diagrams, tables and central and dispersion indices were used to describe the data.

\subsection{Ethical considerations}

The study protocol; was approved by the Ethics Committee of Mashhad University of Medical Sciences. The informed consent was obtained from all the patients' parents and they were ensured about the confidentiality of their information. 


\section{Results}

In this study 220 patients with GI bleeding were admitted to Ghaem Hospital and Dr. Sheikh Hospital (pediatric ward) from June 2012 to June 2014. Of a total 113 study children, 61 (54\%) were boys and 52 (46\%) were girls. Age range of patients varied between newborn infants to 16-year-old children. The etiologies of GI bleeding in various age groups in this study are presented in Table 1 . Patients were divided into five groups according to their age. Records showed that only $17 \%$ of patients had a history of GI bleeding without clear sources. Also, the results showed the patients had upper GI bleeding (40.7\% hematemesis, $38 \%$ coffee ground vomitus) and lower GI bleeding (11.5\% hematochezia, and $17.73 \%$ Melena). Records also showed that in patients who experienced upper GI bleeding, $5.7 \%$ had a history of nonsteroidal anti-inflammatory drugs (NSAIDs) usage. In addition, approximately $6 \%$ had a history of nausea and frequent vomiting. In patients with upper GI bleeding, the minimum and maximum number of hematemesis was reported 1 time in three patients and 15 times in one patient, respectively. Regarding the previous disease history in all patients with upper and lower GH bleeding, 6 (5.3\%) patients had a history of hepatic disease (mostly cirrhosis) that had hematemesis, $1(0.9 \%)$ patient had kidney disease (end stage renal disease), and 4 patients (4\%) had inflammatory bowel disease, who experienced lower GI bleeding. Also, a history of seizures, vitamin $\mathrm{K}$ intake, hypotension, and tachycardia were reported in $8.8 \%, 94.7 \%$, $6.2 \%$ and $23.9 \%$ of patients, based on the past medical histories, respectively. Findings of this study showed that the highest rate of bleeding among all admitted patients was due to prolapse gastropathy $(18.6 \%)$ and esophagitis $(15.9 \%)$, respectively. Other diseases included esophageal varices, gastritis, and coagulopathy that each accounted for $7.1 \%$. Also, the results of the following study demonstrated that esophagitis (18\%) and prolapse gastropathy $(17 \%)$ are the most common cause of intestinal hemorrhage among girls. On the other hand, prolapse gastropathy (19\%) and gastritis (11.5\%) are more prevalent among boys. Regarding age, coagulopathy and maternal blood ingestion are the two most common causes of GI bleeding in newborns, while esophagitis and prolapse gastropathy $(20.6 \%)$ are the most common causes of GI bleeding in infants and children younger than 5 years old. Moreover, the most common causes of GI bleeding were esophagitis and gastritis in children aged 6 to 12 years old, and esophageal varices and peptic ulcer disease (PUD) in children aged 13 to 16 years old.

Table 1. The etiologies of GI bleeding in various age groups in this study

\begin{tabular}{|l|l|l|}
\hline Age group & Number & Etiology \\
\hline Newborns & 10 & Coagulopathy, gastropathy, swallowing blood, colitis \\
\hline $\begin{array}{l}1 \text { month to } 2 \\
\text { years }\end{array}$ & 34 & $\begin{array}{l}\text { Esophagitis, esophageal varices, gastropathy, gastroenteritis, NSAIDs, Mallory-Weiss } \\
\text { tear }\end{array}$ \\
\hline $\begin{array}{l}2 \text { to } 5 \text { years } \\
\text { old }\end{array}$ & 25 & $\begin{array}{l}\text { Esophagitis, esophageal varices, gastropathy, gastroenteritis, NSAIDs, Mallory-Weiss } \\
\text { tear, Duodenal erosions, colitis, Meckel's diverticulum, polyps }\end{array}$ \\
\hline $\begin{array}{l}6 \text { to } 12 \text { years } \\
\text { old }\end{array}$ & 36 & $\begin{array}{l}\text { Esophagitis, esophageal varices, gastropathy, gastroenteritis, NSAIDs, Duodenal } \\
\text { erosions, colitis, Meckel's diverticulum, PUD, Fissure }\end{array}$ \\
\hline $\begin{array}{l}13 \text { to } 16 \text { years } \\
\text { old }\end{array}$ & 8 & Esophageal varices, gastritis, colitis, polyps, PUD \\
\hline
\end{tabular}

\section{Discussion}

GI bleeding may have several etiologies. Studies suggested that duodenal erosions, ulcer, and esophagitis are the most common etiologies of upper GI bleeding. In addition, findings show that anal fissure, polyps, and Meckel's diverticulum are the most common lesions that may lead to lower GI bleeding (16). Chronic use of medication, particularly NSAIDs is also shown to be associated with gastroduodenal injury, gastritis, duodenal ulcers, and gastrointestinal bleeding (17). Also, bacterial infections, especially infection with Helicobacter pylori can cause peptic ulceration resulting in pediatrics' GI bleeding (13). The results of studies have shown that the most common cause of upper GI bleeding in newborn infants and children younger than 2 years are maternal blood ingestion, and gastritis or stress ulcers, respectively $(10,18,19)$. Mallory-Weiss tear was also more prevalent in older children $(20$, 21). But, our findings showed that the most common causes of bleeding in upper GI system are coagulopathy and maternal blood ingestion in newborns, while esophagitis and prolapse gastropathy are the most important etiology of GI bleeding in children younger than 5 years old. Our findings showed that the most important etiology of upper GI bleeding in older children was esophagitis, gastritis, esophageal varices, and PUD. History of drug use, particularly NSAIDs has also been reported by some studies as the main cause of upper GI bleeding $(22,23,30)$, while our findings showed that $36 \%$ had drug use, of whom only $0.9 \%$ had received NSAIDs. Comparison of the etiology of GI bleeding in developed and developing countries has shown that variceal bleeding due to extrahepatic portal vein obstruction is the most common cause of upper GI bleeding in developed countries $(24,25)$. Gastric and duodenal erosions in addition to esophagitis have also been reported as the main causes of pediatrics upper GI bleeding, while 
esophageal varices have been shown to be rare in children younger than 18 months (26-28). On the other hand, it has been previously reported that gastric and duodenal erosions along with esophageal varices and gastric ulcer are the most important causes of pediatrics' upper GI bleeding in Iran $(15,24,29)$. Our findings showed that prolapse gastropathy and esophagitis are more prevalent causes of upper GI bleeding. Moreover, the results of this study showed that esophageal varices were more common in children older than 13 years. Zahmatkeshan et al., in a study in 2012, reported that lower GI bleeding was more prevalent in 2-10-year-old children, and occurs infrequently in neonates. Hematochezia was the greatest common presentation manifested by bloody diarrhea and occult blood. The most prevalent reported finding in colonoscopy was sigmoid colon while the juvenile polyp was the most common pathological finding (31). The current study considered the patients in a short course and not a year-long period, and in various regions of the country, while GI bleeding causes might change by season and location. Also, patients' rights were observed and, in some cases, lack of indication for endoscopy or colonoscopy reduced the available information and all can be considered as study limitations.

\section{Conclusions}

Findings of this study indicated that prolapse gastropathy and esophagitis are more prevalent causes of upper GI bleeding, the main causes of lower GI bleeding are polyp, chronic nonspecific colitis, and proctitis in the study sample. But considering the literature review, various regions of the world have reports indicating variation in the source, etiology, cause and approaches for pediatrics' GI bleeding. Furthermore, multicenter studies considering various countries or review articles investigating the mentioned issues in GI bleeding of children is essential.

\section{Acknowledgments:}

This study, which was based on the research conducted for a medical student's thesis, was supported by a grant from the Vice Chancellor for Research at Mashhad University of Medical Sciences; the approval number was 7159-T.

\section{Conflict of Interest:}

There is no conflict of interest to be declared.

Authors' contributions:

All authors contributed to this project and article equally. All authors read and approved the final manuscript.

\section{References:}

1) Hulme B, Wilcox S. Guidelines on the management of bleeding for palliative care patients with cancer. Yorkshire Palliative Medicine Clinical Guidelines Group, Available from: http://www.Palliativedrugs.com. 2008.

2) Palmer K. Acute upper gastrointestinal haemorrhage. Br Med Bull. 2007; 83(1): 307-24. doi: 10.1093/bmb/ldm023. PMID: 17942452.

3) Rockey DC. Occult and obscure gastrointestinal bleeding: causes and clinical management. Nat Rev Gastroenterol Hepatol. 2010; 7(5): 265-79. doi: 10.1038/nrgastro.2010.42. PMID: 20351759.

4) Ben-Menachem T, Decker GA, Early DS, Evans J, Fanelli RD, Fisher DA, et al. Adverse events of upper GI endoscopy. Gastrointest Endosc. 2012; 76(4): 707-18. doi: 10.1016/j.gie.2012.03.252. PMID: 22985638.

5) Yachimski PS, Friedman LS. Gastrointestinal bleeding in the elderly. Nat Clin Pract Gastroenterol Hepatol. 2008; 5(2): 80-93. doi: 10.1038/ncpgasthep1034. PMID: 18253137.

6) Saljoughian M. Gastrointestinal Bleeding: An Alarming Sign. US Pharm. 2009; 12: 17.

7) Gunjan D, Sharma V, Rana SS, Bhasin DK. Small bowel bleeding: a comprehensive review. Gastroenterol Rep (Oxf). 2014; 2(4): 262-75. doi: 10.1093/gastro/gou025. PMID: 24874805, PMCID: PMC4219139.

8) Vernava AM, 3rd, Moore BA, Longo WE, Johnson FE. Lower gastrointestinal bleeding. Dis Colon Rectum. 1997; 40(7): 846-58. doi: 10.1007/BF02055445. PMID: 9221865.

9) Manning-Dimmitt LL, Dimmitt SG, Wilson GR. Diagnosis of gastrointestinal bleeding in adults. Am Fam Physician. 2005; 71(7): 1339-46.

10) Owensby S, Taylor K, Wilkins T. Diagnosis and Management of Upper Gastrointestinal Bleeding in Children. J Am Board Fam Med. 2015; 28(1): 134-45. doi: 10.3122/jabfm.2015.01.140153. PMID: 25567834.

11) Brown RL, Azizkhan RG. Gastrointestinal bleeding in infants and children: Meckel's diverticulum and intestinal duplication. Semin Pediatr Surg. 1999; 8(4): 202-9. 
12) Neidich GA, Cole SR. Gastrointestinal Bleeding. Pediatr Rev. 2014; 35(6): 243-54. doi: 10.1542/pir.35-6243. PMID: 24891598.

13) Boyle JT. Gastrointestinal bleeding in infants and children. Pediatr Rev. 2008; 29(2): 39-52.

14) Flynn DM, Booth IW. Investigation and management of gastrointestinal bleeding in children. Current Paediatrics. 2004; 14(7): 576-85. doi: 10.1016/j.cupe.2004.09.001.

15) Masoodi M, Saberifiroozi M. Etiology and outcome of acute gastrointestinal bleeding in iran: a review article. Middle East J Dig Dis. 2012; 4(4): 193-8.

16) Hillemeier C, Gryboski JD. Gastrointestinal bleeding in the pediatric patient. Yale J Biol Med. 1984; 57(2): $135-47$.

17) Cardile S, Martinelli M, Barabino A, Gandullia P, Oliva S, Di Nardo G, et al. Italian survey on nonsteroidal anti-inflammatory drugs and gastrointestinal bleeding in children. World Journal of Gastroenterology. 2016; 22(5): 1877-83. doi: 10.3748/wjg.v22.i5.1877.

18) Genel S, Lucia SM, Daniel SG, Emanuela F. Gastrointestinal Bleeding in Children can have Many Causes. Pharm Anal Acta. 2016; 7: e184. doi: 10.4172/2153-2435.1000e184.

19) Nithiwathanapong $C$, Reungrongrat $S$, Ukarapol N. Prevalence and risk factors of stress-induced gastrointestinal bleeding in critically ill children. World J Gastroenterol. 2005; 11(43): 6839-42.

20) Romaniszyn BK, Panas M, Czkwianianc, Małecka P. Mallory-Weiss syndrome in children. Dis Esophagus. 1999; 12(1): 65-7. doi: 10.1046/j.1442-2050.1999.00006.x.

21) Bishop PR, Nowicki MJ, Parker PH. Vomiting-Induced Hematemesis in Children: Mallory-Weiss Tear or Prolapse Gastropathy? J Pediatr Gastroenterol Nutr. 2000; 30(4): 436-41. doi: 10.1097/00005176200004000-00017. PMID: 10776958.

22) Musumba C, Jorgensen A, Sutton L, Van Eker D, Moorcroft J, Hopkins M, et al. The relative contribution of NSAIDs and Helicobacter pylori to the aetiology of endoscopically-diagnosed peptic ulcer disease: observations from a tertiary referral hospital in the UK between 2005 and 2010. Aliment Pharmacol Ther. 2012; 36(1): 48-56. doi: 10.1111/j.1365-2036.2012.05118.x. PMID: 22554233.

23) Laporte JR, Ibanez L, Vidal X, Vendrell L, Leone R. Upper gastrointestinal bleeding associated with the use of NSAIDs: newer versus older agents. Drug Saf. 2004; 27(6): 411-20.

24) Rafeey M, Shoaran M, Majidy H. Diagnostic Endoscopy and Clinical Characteristics of Gastrointestinal Bleeding in Children: a 10-Year Retrospective Study. Iran Red Crescent Med J. 2013; 15(9): 794-7.

25) Chaudhary N, Mehrotra S, Srivastava M, Nundy S. Management of bleeding in extrahepatic portal venous obstruction. Internat J Hepatol. 2013; 2013.

26) Carvalho RS, Michail S, Ashai-Khan F, Mezoff AG. An update on pediatric gastroenterology and nutrition: a review of some recent advances. Current problems in pediatric and adolescent health care. 2008; 38(7): 204-28. doi: 10.1016/j.cppeds.2008.06.002. PMID: 18647667.

27) Cox K, Ament ME. Upper Gastrointestinal Bleeding in Children and Adolescents. Pediatrics. 1979; 63(3): 408-13. PMID: 312485.

28) Gana JC, Turner D, Mieli-Vergani G, Davenport M, Miloh T, Avitzur Y, et al. A Clinical Prediction Rule and Platelet Count Predict Esophageal Varices in Children. Gastroenterology. 2011; 141(6): 2009-16. doi: 10.1053/j.gastro.2011.08.049. PMID: 21925123.

29) Dehghani SM, Haghighat M, Imanieh MH, Tabebordbar MR. Upper gastrointestinal bleeding in children in Southern Iran. Indian J Pediatr. 2009; 76(6): 635-8. doi: 10.1007/s12098-009-0092-3. PMID: 19390793.

30) Zahmatkeshan M, Fallahzadeh E, Najib KH, Geramizadeh B, Haghighat M, Imanieh M. Etiology of Lower Gastrointestinal Bleeding in Children: A Single Center Experience from Southern Iran. Middle East J Dig Dis. 2012; 4(4): 216-23. PMID: 24829660, PMCID: PMC3990129.

31) Dubay SRK, Bhadauria N, Shukla M, Mittal P, Arya A. Clinico-etiological pattern of upper gastrointestinal bleeding in children. International Journal of Contemporary Pediatrics. 2016; 4(1): 132-5. doi: 10.18203/2349-3291.ijcp20164592. 